\title{
Insights into the transfer of silicon isotopes into the sediment record
}

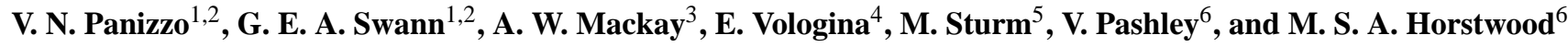 \\ ${ }^{1}$ School of Geography, Centre for Environmental Geochemistry, University of Nottingham, University Park, Nottingham, \\ NG7 2RD, UK \\ ${ }^{2}$ Centre for Environmental Geochemistry, British Geological Survey, Keyworth, Nottingham, NG12 5GG, UK \\ ${ }^{3}$ Environmental Change Research Centre, Department of Geography, University College London, Gower Street, London, \\ WC1E 6BT, UK \\ ${ }^{4}$ Institute of Earth's Crust, Siberian Branch of the Russian Academy of Sciences, 128 ul. Lermontov, Irkutsk, 664033, Russia \\ ${ }^{5}$ Eawag-ETH, Swiss Federal Instiute of Aquatic Science and Technology, 8600, Dübendorf, Switzerland \\ ${ }^{6}$ NERC Isotope Geosciences Laboratory, British Geological Survey, Keyworth, Nottingham, NG12 5GG, UK
}

Correspondence to: V. N. Panizzo (virginia.panizzo@nottingham.ac.uk)

Received: 22 May 2015 - Published in Biogeosciences Discuss.: 23 June 2015

Revised: 9 December 2015 - Accepted: 10 December 2015 - Published: 15 January 2016

\begin{abstract}
The first $\delta^{30} \mathrm{Si}_{\text {diatom }}$ data from lacustrine sediment traps are presented from Lake Baikal, Siberia. Data are compared with March surface water (upper $180 \mathrm{~m}$ ) $\delta^{30} \mathrm{Si}_{\mathrm{DSi}}$ compositions for which a mean value of $+2.28 \%$ \pm 0.09 (95\% confidence) is derived. This value acts as the prediatom bloom baseline silicic acid isotopic composition of waters $\left(\delta^{30} \mathrm{Si}_{\mathrm{DSi}}\right.$ initial $)$. Open traps were deployed along the depth of the Lake Baikal south basin water column between 2012 and 2013. Diatom assemblages display a dominance ( $>85 \%$ ) of the spring/summer bloom species Synedra acus var radians, so that $\delta^{30} \mathrm{Si}_{\text {diatom }}$ compositions reflect predominantly spring/summer bloom utilisation. Diatoms were isolated from open traps and, in addition, from 3-monthly (sequencing) traps (May, July and August 2012) for $\delta^{30} \mathrm{Si}_{\text {diatom }}$ analyses. Mean $\delta^{30} \mathrm{Si}_{\text {diatom }}$ values for open traps are $+1.23 \% \circ \pm 0.06$ (at $95 \%$ confidence and MSWD of $2.9, n=10$ ). Total dry mass sediment fluxes are highest in June 2012, which we attribute to the initial export of the dominant spring diatom bloom. We therefore argue that May $\delta^{30} \mathrm{Si}_{\text {diatom }}$ signatures $(+0.67 \%$ o $\pm 0.06,2 \sigma)$ when compared with mean upper water $\delta^{30} \mathrm{Si}$ DSi initial (e.g. prebloom) signatures can be used to provide a snapshot estimation of diatom uptake fractionation factors $\left(\epsilon_{\text {uptake }}\right)$ in Lake Baikal. A $\epsilon_{\text {uptake }}$ estimation of $-1.61 \%$ is therefore derived, although we emphasise that synchronous monthly $\delta^{30} \mathrm{Si}_{\mathrm{DSi}}$ and $\delta^{30} \mathrm{Si}_{\text {diatom }}$ data would be needed to provide more robust estimations and therefore more rigorously test this, particularly when taking into consideration any progres-
\end{abstract}

sive enrichment of the DSi pool as blooms persist. The nearconstant $\delta^{30} \mathrm{Si}_{\text {diatom }}$ composition in open traps demonstrates the full preservation of the signal through the water column and thereby justifies the use and application of the technique in biogeochemical and palaeoenvironmental research. Data are finally compared with lake sediment core samples, collected from the south basin. Values of $+1.30 \%$ $\pm 0.08(2 \sigma)$ and $+1.43 \% \circ \pm 0.13(2 \sigma)$ were derived for cores BAIK13$1 \mathrm{C}(0.6-0.8 \mathrm{~cm}$ core depth) and at BAIK13-4F $(0.2-0.4 \mathrm{~cm}$ core depth) respectively. Trap data highlight the absence of a fractionation factor associated with diatom dissolution $\left(\epsilon_{\text {dissolution}}\right)$ (particularly as Synedra acus var radians, the dominant taxa in the traps, is very susceptible to dissolution) down the water column and in the lake surface sediments, thus validating the application of ${ }^{30} \mathrm{Si}_{\text {diatom }}$ analyses in Lake Baikal and other freshwater systems, in palaeoreconstructions.

\section{Introduction}

Records of diatom silicon isotopes $\left(\delta^{30} \mathrm{Si}_{\text {diatom }}\right)$ provide a key means to investigate changes in the global silicon cycle (De La Rocha, 2006; Hendry and Brzezinski, 2014; Leng et al., 2009; Tréguer and De La Rocha, 2013). Through measurements of $\delta^{30} \mathrm{Si}$ (including diatoms $\delta^{30} \mathrm{Si}_{\text {diatom }}$ and the dissolved silicon (DSi) phase $\delta^{30} \mathrm{Si}_{\mathrm{DSi}}$ ) it has been possible to elucidate a more comprehensive understanding of biogeo- 
chemical cycling both on continents (e.g. Cockerton et al., 2013; Opfergelt et al., 2011) and in the ocean (Fripiat et al., 2012) allowing, for example, an assessment of the role of the marine biological pump in regulating past changes in atmospheric $p \mathrm{CO}_{2}$ (aq) (e.g. Pichevin et al., 2009). These studies and their interpretations rely on work that has examined the mechanics of diatom silicon isotope fractionation, demonstrating an enrichment factor ( $\epsilon_{\text {uptake }}$ : resulting from the discrimination by diatoms against the heavier ${ }^{30} \mathrm{Si}$ isotope) of $-1.1 \% \circ \pm 0.4$ to $-1.2 \% \circ \pm 0.2$. In this case $\epsilon_{\text {uptake }}$ is the per mil enrichment between the resulting product and its substrate. Estimations of $\epsilon_{\text {uptake }}\left(-1.1 \% \circ \pm 0.4\right.$ to $\left.-1.2 \%_{\circ} \pm 0.2\right)$ have to date shown it to be independent of temperature, $p \mathrm{CO}_{2 \text { (aq) }}$ and other vital effects (De La Rocha et al., 1997; Fripiat et al., 2011; Milligan et al., 2004; Varela et al., 2004), although more recent work on marine diatoms in laboratory cultures has argued for a species-dependent fractionation effect (Sutton et al., 2013). In this case, $\epsilon_{\text {uptake }}$ estimations were documented between $-0.53 \% \circ \pm 0.11$ and $-0.56 \% \circ \pm 0.07$ for the Fragilariopsis kerguelensis species (depending on the culturing strains used) and up to $-2.09 \% \circ \pm 0.09$ for the Chaetocerous brevis species (Sutton et al., 2013).

A further assumption is that the isotopic signatures captured by diatoms in the photic zone are faithfully transported through the water column and into the sediment record, without alteration from dissolution or other processes. This has been questioned by evidence from diatom cultures which have revealed a diatom dissolution induced fractionation $\left(\epsilon_{\text {dissolution}}\right)$ of $-0.55 \pm 0.05 \%$ (from the preferential release of the heavier ${ }^{30} \mathrm{Si}$ isotope into the dissolved phase, over the lighter ${ }^{28} \mathrm{Si}$ during dissolution) that is independent of inter-species variations or temperature (Demarest et al., 2009), although the importance and indeed existence of an $\epsilon_{\text {dissolution }}$ has been questioned by studies in the natural environment (Egan et al., 2012) and the laboratory (Wetzel et al., 2014). Whilst measurements of $\delta^{30} \mathrm{Si}_{\text {diatom }}$ from sediment traps (Varela et al., 2004), core-tops (Egan et al., 2012) and in situ water column biogenic silica (BSi) (Fripiat et al., 2012) in marine systems have been used in isolation, an integrated record is needed to document the fate of $\delta^{30} \mathrm{Si}_{\text {diatom }}$ as diatoms sink through the water and become incorporated into the sediment record, particularly in a lacustrine system where hitherto no such work has taken place. Here, we present prediatom bloom $\delta^{30} \mathrm{Si}_{\mathrm{DS}}$ initial and $\delta^{30} \mathrm{Si}_{\text {diatom }}$ data from Lake Baikal, Siberia (Fig. 1). By analysing samples from sediment traps through the $>1600 \mathrm{~m}$ water column and a sediment core from the same site (Fig. 1), we document the good transfer of the photic zone $\delta^{30} \mathrm{Si}_{\mathrm{DS}}$ signature into diatoms and into the sediment record.

Unlike in ocean systems, where $\delta^{30} \mathrm{Si}_{\text {diatom }}$ analyses have been used as a tracer for past surface water DSi utilisation and/or supply (De La Rocha, 2006; Pichevin et al., 2012; Panizzo et al., 2013), its application in lake systems has not been as fully explored. To date, only a handful of studies have aimed to validate the proxy in lacustrine systems via in situ

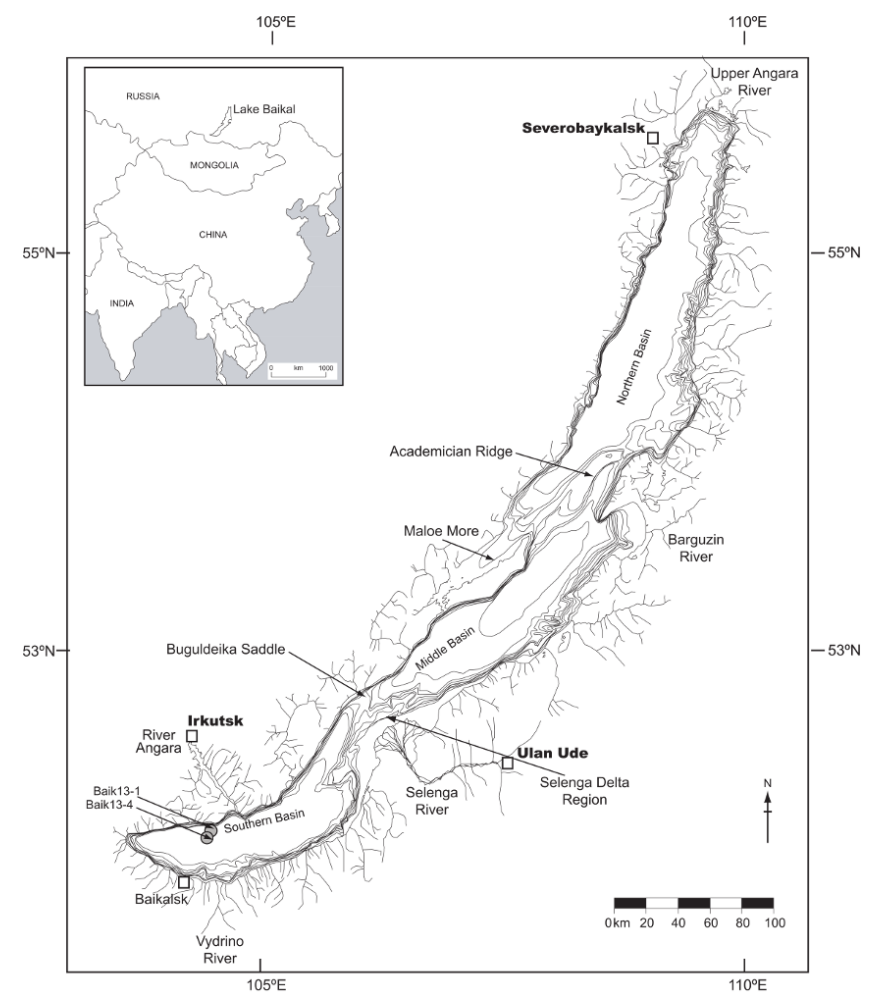

Figure 1. Map of the Lake Baikal catchment, showing dominant inflowing rivers and the Angara River outflow. The three catchments are identified as well as the location of sites BAIK13-1 and BAIK13-4, where cores, sediment traps and water column profiles were collected.

measurements of seasonal DSi and BSi (Alleman et al., 2005; Opfergelt et al., 2011). Here we present a further validation of the proxy (e.g. estimations of $\epsilon_{\text {uptake }}$ ), which also aims to address more fully the preservation of the signal to the sediment record $\left(\epsilon_{\text {dissolution }}\right)$, which is of great importance in Lake Baikal where dissolution of diatoms is prevalent. This is particularly important if measurements of $\delta^{30} \mathrm{Si}_{\text {diatom }}$ are to be used to reconstruct past DSi utilisation and/or supply in relation to climatic and/or environmental perturbations (StreetPerrott et al., 2008; Swann et al., 2010). Furthermore, with recent evidence highlighting the perturbation of the steadystate delivery of DSi to ocean systems as a result of lacustrine burial (Frings et al., 2014), the application of $\delta^{30} \mathrm{Si}_{\text {diatom }}$ techniques may be of great value in the future.

The main objectives of this study are to therefore

1. use annual sediment trap data as a means to document the good transfer of surface $\delta^{30} \mathrm{Si}_{\text {diatom }}$ compositions to the sediment record and validate the use of $\delta^{30} \mathrm{Si}_{\text {diatom }}$ methods in Lake Baikal as a proxy for DSi utilisation/supply, and

2. use sediment trap data, for the first time, to attempt to validate fundamental principles of $\epsilon_{\text {uptake }}$ and $\epsilon_{\text {dissolution, }}$, 
in Lake Baikal, which to date have been more widely investigated in marine systems.

\section{Lake Baikal}

Lake Baikal $\left(103^{\circ} 43^{\prime}-109^{\circ} 58^{\prime} \mathrm{E}\right.$ and $\left.51^{\circ} 28^{\prime}-55^{\circ} 47^{\prime} \mathrm{N}\right)$ is the world's deepest and most voluminous lake $\left(23615 \mathrm{~km}^{3}\right)$ containing one-fifth of global freshwater not stored in glaciers and ice caps (Atlas Baikalia, 1993; Gronskaya and Litova, 1991; Sherstyankin et al., 2006). Divided into three basins (south, central and north), the Academician Ridge separates the central (max depth $1642 \mathrm{~m}$ ) and north (max depth $904 \mathrm{~m}$ ) basins, while the Buguldeika ridge running north-easterly from the shallow waters of the Selenga delta divides the south (max depth $1460 \mathrm{~m}$ ) and central basins (Sherstyankin et al., 2006) (Fig. 1). This study will focus on the southern basin (where sediment traps were deployed; Fig. 1), which has an estimated average depth of $853 \mathrm{~m}$ (Sherstyankin et al., 2006) and a long water residence time of 377-400 years (Gronskaya and Litova, 1991), although the residency time of silicon in the lake is estimated to be shorter at 170 years (Falkner et al., 1997).

Diatom dissolution in Lake Baikal occurs mainly at the bottom sediment-water interface as opposed to during downcolumn settling of diatoms (Ryves et al., 2003), with Müller et al. (2005) showing that remineralisation processes are an important constituent of surface water nutrient renewal. Lake Baikal may be thought of as having two differing water masses with the mesothermal maximum (MTM) separating them at a depth of ca. 200-300 m (Kipfer and Peeters, 2000; Ravens et al., 2000). In the upper waters (above ca. 200$300 \mathrm{~m}$ ), both convective and wind forced mixing occurs twice a year (Shimaraev et al., 1994; Troitskaya et al., 2014) during spring and autumn overturn periods. These overturn periods follow (precede) ice-off (on) respectively and are separated by a period of summer surface water stratification (e.g. above the MTM). Diatom productivity in the lake is most notable during these overturn periods although spring diatom blooms tend to dominate annual productivity. Below ca. $300 \mathrm{~m}$ (e.g. below the MTM), waters are permanently stratified (Ravens et al., 2000; Shimaraev et al., 1994; Shimaraev and Granin, 1991), although despite this the water column of Lake Baikal is oxygenated throughout, and it is estimated that ca. $10 \%$ of its deeper water is renewed each year through downwelling episodes (Hohmann et al., 1997; Kipfer et al., 1996; Shimaraev and Granin, 1991; Weiss et al., 1991).

\section{Methods}

\subsection{Sample locations}

Upper water column (top $180 \mathrm{~m}$ ) samples for DSi concentrations and $\delta^{30} \mathrm{Si}_{\mathrm{DSi}}$ analyses were collected on two occasions, when the lake was ice-covered, less than 2 weeks apart, in
March 2013 at site BAIK13-1 (sampling a and b; Table 1) in the south basin of Lake Baikal (Fig. 1; 51.76778 $\mathrm{N}$ and $104.41611^{\circ} \mathrm{E}$ ) using a $2 \mathrm{~L}$ Van Dorn sampler. This sampling coincided with the period when (1) riverine and precipitation inflows to the lake are minimal, and (2) photosynthetic activity in the lake was low (as demonstrated by negligible in situ chlorophyll $a$ measurements). We argue that the average pre-bloom DSi and $\delta^{30} \mathrm{Si}_{\mathrm{DSi}}$ values represent the baseline nutrient conditions of the upper waters of the south basin. Samples were filtered on collection through $0.4 \mu \mathrm{m}$ polycarbonate filters (Whatman) before storage in $125 \mathrm{~mL}$ acid-washed LDPE bottles, and acidified with Superpure $\mathrm{HCl}$ to a $\mathrm{pH}$ above 2 .

At the same site, samples were collected from open sediment traps $(n=10)$ deployed by EAWAG and the Institute of Earth's Crust/SB-RAS between March 2012 and March 2013 (from 100 to $1350 \mathrm{~m}$ water depth; Table 2) and from monthly sequencing traps $(n=3)$ on the same array at a water depth of $100 \mathrm{~m}$. For all open traps and for three of the monthly traps (A4: 17 May to 7 June 2012, A6: 4 July to 31 July 2012 and A7: 31 July 2012 to 21 August 2012) it was possible to extract sufficient diatoms for isotope analysis (see below).

Sediment cores were collected from site BAIK13-1 $\left(51.76778^{\circ} \mathrm{E}\right.$ and $104.41611^{\circ} \mathrm{N}$; Fig. 1) and from the nearby BAIK13-4 (51.69272 ${ }^{\circ} \mathrm{N}$ and $104.30003^{\circ} \mathrm{E}$; Fig. 1) using a UWITEC corer through ca. $78-90 \mathrm{~cm}$ of ice with onsite sub-sampling at $0.25 \mathrm{~cm}$ intervals. Both sediment cores were dated using ${ }^{210} \mathrm{~Pb}$ dating (at University College London) using the CRS (constant rate of supply) model (Appleby and Oldfield, 1978), which is in agreement with the individual ${ }^{137} \mathrm{Cs}$ record for the two cores. Sub-samples corresponding to $0.6-0.8 \mathrm{~cm}$ at BAIK13-1 (core BAIK13-1C; age $=2007 \mathrm{AD} \pm 2$ years) and $0.2-0.4 \mathrm{~cm}$ at BAIK13-4 (core BAIK13-4F; age $=2012 \mathrm{AD} \pm 7$ years: the sampling period covered by the sediment traps) were processed to obtain diatoms for $\delta^{30} \mathrm{Si}_{\text {diatom analysis. }}$

\subsection{Analytical methods}

\subsubsection{Diatom counting}

To assess the taxonomic composition of diatoms in the open sediment trap samples, diatom slides were prepared using a protocol that omits any chemical treatments or centrifugation in order to minimise further diatom dissolution and valve breakage (see Mackay et al., 1998, for full details). Slides were counted using a Zeiss light microscope with oil immersion and phase contrast at $\times 1000$ magnification. Microspheres at a known concentration of $8.2 \times 10^{6}$ spheres $\mathrm{mL}^{-1}$ were added to all samples in order to calculate diatom concentrations. 
Table 1. $\delta^{30} \mathrm{Si}_{\mathrm{DSi}}$, respective uncertainties (2 $\sigma$, unless otherwise stated) and DSi concentrations for sampling in South Basin of Lake Baikal at site BAIK13-1 in March 2013. Bold values correspond to the weighted average mean values (with respective errors) of data presented. Data are plotted in Fig. 3.

\begin{tabular}{lrrrrrr}
\hline & Depth (m) & DSi (ppm) & $\delta^{30} \mathrm{Si}_{\text {DSi }}$ & $2 \sigma$ & $\delta^{29} \mathrm{Si}_{\mathrm{DSi}}$ & $2 \sigma$ \\
\hline BAIK13-1a & 0.4 & 1.22 & +2.34 & $0.15^{2}$ & +1.22 & $0.10^{2}$ \\
3 Mar 2013 & 10 & 1.19 & +2.17 & $0.15^{2}$ & +1.18 & $0.09^{2}$ \\
& 24 & 1.17 & +2.55 & $0.15^{2}$ & +1.29 & $0.10^{2}$ \\
& 40 & 1.12 & +2.18 & 0.11 & +1.18 & 0.06 \\
& 100 & 1.06 & $+2.22^{1}$ & 0.31 & $+1.27^{1}$ & 0.19 \\
& 180 & 0.66 & +2.40 & 0.08 & +1.23 & 0.04 \\
\hline BAIK13-1b & 1 & 0.74 & +2.16 & 0.09 & +1.14 & 0.04 \\
12 Mar 2013 & 10 & 1.21 & +2.44 & $0.15^{2}$ & +1.20 & $0.05^{2}$ \\
& 20 & 1.15 & +2.28 & $0.10^{2}$ & +1.17 & $0.04^{2}$ \\
& 50 & 1.16 & +2.29 & $0.16^{2}$ & +1.26 & $0.11^{2}$ \\
\hline W.A MEAN & & & $+\mathbf{2 . 2 8}$ & $\mathbf{0 . 0 9}$ & $+\mathbf{1 . 1 9}$ & $\mathbf{0 . 0 3}^{2}$ \\
MSDW & & & $\mathbf{4 . 1}$ & & $\mathbf{1 . 9}$ & \\
\hline
\end{tabular}

${ }^{1}$ This water sample was not pre-concentrated; refer to methods. ${ }^{2}$ These water sample values are weighted averages for sample replicates that are analytically robust. These errors are at the $95 \%$ confidence interval.

Table 2. Open and sequencing trap (sampling interval 2012-2013) $\delta^{30} \mathrm{Si}_{\text {diatom }}$ data and respective uncertainties (2 $\sigma$, unless otherwise stated). Mean values for open trap $\delta^{30} \mathrm{Si}_{\text {diatom }}$ compositions are provided (in bold) along with $95 \%$ confidence and the population MSWD value. Mean values for sequencing trap $\delta^{30} \mathrm{Si}_{\text {diatom }}$ are also displayed in bold, with respective $2 \mathrm{SD}$ errors. Respective water column depths for open traps are presented along with the relative abundance of $S$. acus var radians (data not available for sequencing traps). All open trap data (Z2-Z11) are plotted in Fig. 4.

\begin{tabular}{|c|c|c|c|c|c|c|c|}
\hline Code & Depth (m) & $\delta^{30} \mathrm{Si}_{\mathrm{DSi}}$ & $2 \sigma$ & $\delta^{29} \mathrm{Si}_{\mathrm{DSi}}$ & $2 \sigma$ & $\begin{array}{l}\text { Sediment flux } \\
\left(\mathrm{mg} \mathrm{m}^{-2} \mathrm{~d}^{-1}\right)\end{array}$ & $\begin{array}{r}\text { S. acus } \\
\text { var radians }\end{array}$ \\
\hline \multicolumn{8}{|c|}{ Open sediment traps } \\
\hline $\mathrm{Z} 2$ & 100 & +1.19 & 0.12 & +0.62 & 0.07 & 1584 & $90 \%$ \\
\hline $\mathrm{Z3}$ & 200 & +1.28 & 0.11 & +0.70 & 0.06 & 1503 & $90 \%$ \\
\hline $\mathrm{Z4}$ & 300 & $+1.11^{1}$ & 0.15 & $+0.61^{1}$ & 0.08 & 1686 & $93 \%$ \\
\hline $\mathrm{Z5}$ & 400 & $+1.32^{1}$ & 0.16 & $+0.69^{1}$ & 0.10 & 1772 & $93 \%$ \\
\hline Z6 & 600 & $+1.38^{1}$ & 0.15 & $+0.71^{1}$ & 0.10 & 1942 & $88 \%$ \\
\hline $\mathrm{Z7}$ & 700 & +1.38 & 0.17 & +0.69 & 0.11 & 1997 & $94 \%$ \\
\hline $\mathrm{Z8}$ & 900 & +1.26 & 0.14 & +0.66 & 0.10 & 1980 & $92 \%$ \\
\hline Z9 & 1100 & +1.21 & 0.13 & +0.60 & 0.10 & 1887 & $94 \%$ \\
\hline $\mathrm{Z} 10$ & 1300 & $+1.17^{1}$ & 0.12 & $+0.61^{1}$ & 0.07 & 1943 & $92 \%$ \\
\hline $\mathrm{Z} 11$ & 1350 & +1.25 & 0.11 & +0.62 & 0.10 & 1999 & $86 \%$ \\
\hline W.A Mean & & +1.23 & $0.06^{1}$ & +0.63 & $\mathbf{0 . 0 3}{ }^{1}$ & & \\
\hline MSWD & & 2.9 & & 1.6 & & & \\
\hline \multicolumn{8}{|c|}{ Sequencing traps } \\
\hline A4 & May & +0.67 & 0.06 & +0.36 & 0.04 & 1650 & \\
\hline A6 & Jul & +1.22 & 0.08 & +0.53 & 0.09 & 175 & \\
\hline A7 & Aug & +1.37 & 0.07 & +0.69 & 0.03 & 169 & \\
\hline Mean & & $+\mathbf{1 . 0 9}$ & $\mathbf{0 . 7 4}(2 \mathrm{SD})$ & $+\mathbf{0 . 5 3}$ & $\mathbf{0 . 3 3}(2 \mathrm{SD})$ & & \\
\hline \multicolumn{8}{|c|}{ Sediment cores } \\
\hline BAIK13-1C & $0.6-0.8 \mathrm{~cm}$ & +1.30 & 0.08 & +0.68 & 0.05 & & \\
\hline BAIK13-4F & $0.2-0.4 \mathrm{~cm}$ & +1.43 & 0.13 & +0.75 & 0.04 & & \\
\hline
\end{tabular}

\footnotetext{
1 These water sample values are weighted averages for sample replicates that are analytically robust. These errors are at the $95 \%$ confidence interval.
} 


\subsubsection{Silicon isotope sample preparation}

Prior to isotope analysis, $0.7-1.0 \mathrm{~g}$ of sediment core (dry weight) and trap material (wet weight) was digested of organic matter with analytical grade $\mathrm{H}_{2} \mathrm{O}_{2}(30 \%)$ at $75^{\circ} \mathrm{C}$ for ca. $12 \mathrm{~h}$. This was followed by heavy density separation using sodium polytungstate (Sometu Europa) at $2500 \mathrm{rpm}$ for $15 \mathrm{~min}$, with centrifuge break off, at a specific gravity between 2.10 and $2.25 \mathrm{~g} \mathrm{~mL}^{-1}$ (adjusted to suit sample contamination) to remove lithogenic particles and clays. Samples were washed (up to 10 times) with deionised water at $2500 \mathrm{rpm}$ for $5 \mathrm{~min}$ before visual inspection for contaminants at $\times-400$ magnification on a Zeiss inverted light microscope. All samples showed no evidence of external contaminants that would impact the isotopic measurements (as displayed in light microscopy images; (Fig. 2).

Silicon concentrations on all 25 samples (10 March lake water and 13 diatom opal trap samples (open $\mathrm{Z}$ and sequencing A traps) and 2 lake surface sediment samples) were measured on an Inductively Coupled Plasma-Mass Spectrometer (ICP-MS) (Agilent Technologies 7500) at the British Geological Survey. Diatom samples were digested using the $\mathrm{NaOH}$ fusion method (Georg et al., 2006) with 1-3 mg of powdered material fused with a $200 \mathrm{mg} \mathrm{NaOH}$ (Quartz Merk) pellet in a silver crucible, covered within a Ni crucible with lid, for $10 \mathrm{~min}$ in a muffle furnace at $730^{\circ} \mathrm{C}$. Following fusion, silver crucibles were placed in a $30 \mathrm{~mL}$ Teflon Savillex beaker and rinsed with Milli Q water before adding Ultra Purity Acid (UPA) HCl (Romil) to reach a pH above 2. Samples were sonicated to ensure they were fully dissolved and mixed before leaving them overnight in the dark.

Water samples with DSi concentrations $<1.5 \mathrm{ppm}$ were pre-concentrated prior to column chemistry by evaporating $30 \mathrm{~mL}$ of sample to $5 \mathrm{~mL}$ at $70^{\circ} \mathrm{C}$ on a hotplate in a Teflon Savillex beaker in a laminar flow hood. This follows Hughes et al. (2011), who showed no evaporative alteration of silicon in samples and reference materials, provided samples are not evaporated to dryness. This was not conducted for sample BAIK1a-100 $\mathrm{m}$ as there was insufficient sample to do so (Table 1). Following pre-concentration, samples (and reference and validation materials) were purified by passing a known volume (between 1 and $2.5 \mathrm{~mL}$ depending on $\mathrm{Si}$ concentration) through a $1.8 \mathrm{~mL}$ cationic resin bed (BioRad AG50WX12) (Georg et al., 2006) and eluted with $3 \mathrm{~mL}$ of Milli Q water in order to obtain an optimal Si concentration of between 3 and $10 \mathrm{ppm}$.

\subsubsection{Silicon isotope analysis}

All isotope analyses were carried out on a ThermoScientific Neptune Plus MC-ICP-MS (multi collector inductively coupled plasma mass spectrometer), operated in wetplasma mode using the method/settings outlined in Cockerton et al. (2013). To overcome any analytical bias due to differing matrices, samples and reference materials were acid- ified using $\mathrm{HCl}$ (to a concentration of $0.05 \mathrm{M}$, using Romil UPA) and sulfuric acid (to a concentration of $0.003 \mathrm{M}$, using Romil UPA) following the recommendations of Hughes et al. (2011), the principle being that doping samples and standards alike, above and beyond the natural abundance of $\mathrm{Cl}^{-}$and $\mathrm{SO}_{4}^{2-}$ will evoke a similar mass bias response in each. All samples and reference materials were doped with $\sim 300 \mathrm{ppb}$ magnesium ( $\mathrm{Mg}$, Alfa Aesar SpectraPure) to allow the data to be corrected for the effects of instrument-induced mass bias (Cardinal et al., 2003; Hughes et al., 2011). In order to do this, Mg concentrations were the same in both standard and samples.

Background signal contributions on ${ }^{28} \mathrm{Si}$ were typically between 50 and $100 \mathrm{mV}$. Total procedural blanks for water samples were $15 \mathrm{ng}$ compared to typical sample amounts of $4000 \mathrm{ng}$. Procedural blank compositions are difficult to accurately measure (due to exceedingly low $\mathrm{Si}$ signals), but as a worst-case scenario may have deviated from sample compositions by ca. $0.38 \%$, contributing up to a ca. $0.02 \%$ o shift in typical sample compositions. This increases to ca. $0.20 \%$ compositional shift in exceptional cases, i.e. for one sample replicate (BAIK13-1 100 m), which has a Si concentration of much less than $1 \mathrm{ppm}$. Fusion procedural blanks were ca. $42 \mathrm{ng}$ compared to typical fusion sample amounts of $4900 \mathrm{ng}$. Again, procedural blank compositions are difficult to accurately measure, but may have deviated from sample compositions by ca. $0.04 \%$, contributing up to a less than $0.01 \%$ shift in the sample compositions.

The validation material (diatomite) was analysed repeatedly during each analytical session and a secondary reference material (an in-house river water sample, RMR4) was also periodically analysed. Data were corrected online for mass bias using an exponential function, assuming ${ }^{24} \mathrm{Mg} /{ }^{25} \mathrm{Mg}=0.126633$. All uncertainties are reported at $2 \sigma$ absolute, and incorporate an excess variance derived from the diatomite validation material, which was quadratically added to the analytical uncertainty of each measurement. $\delta^{30} \mathrm{Si}: \delta^{29} \mathrm{Si}$ ratios of all data were compared with the mass-dependent fractionation line (1.93), with which all data comply (Johnson et al., 2004). Long-term (ca. 2 years) variance for the method is the following: diatomite $=+1.23 \%$ o \pm $0.16(2 \sigma, n=210)$ (consensus value of $+1.26 \%$ o $\pm 0.2,2 \sigma$; Reynolds et al. (2007)) and RMR4 $=+0.88 \% \circ \pm 0.20(2 \sigma$, $n=42)$.

\section{Results}

Below-ice $\delta^{30} \mathrm{Si}_{\mathrm{DSi}}$ and DSi values in March 2013 from the top $1 \mathrm{~m}$ of the water column, collected within 2 weeks of each other, are $+2.34 \% \circ \pm 0.15(2 \sigma), 1.22 \mathrm{ppm}$ and $+2.16 \%$ \pm $0.09(2 \sigma), 0.74 \mathrm{ppm}$ for BAIK13-1a and BAIK13-1b respectively (Fig. 3; Table 1). DSi compositions show some variability with depth at both sites, with overall trends showing decreasing concentrations with depth (Fig. 3), with the ex- 

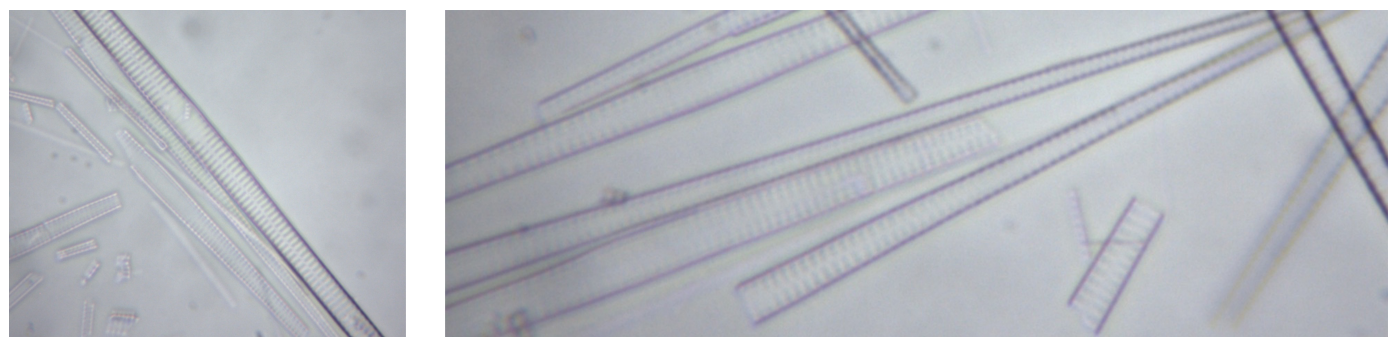

Figure 2. Light microscopy images of open trap diatom species from Lake Baikal $(\times 1000)$. Images show the purity of samples used for $\delta^{30} \mathrm{Si}_{\text {diatom }}$ analyses.
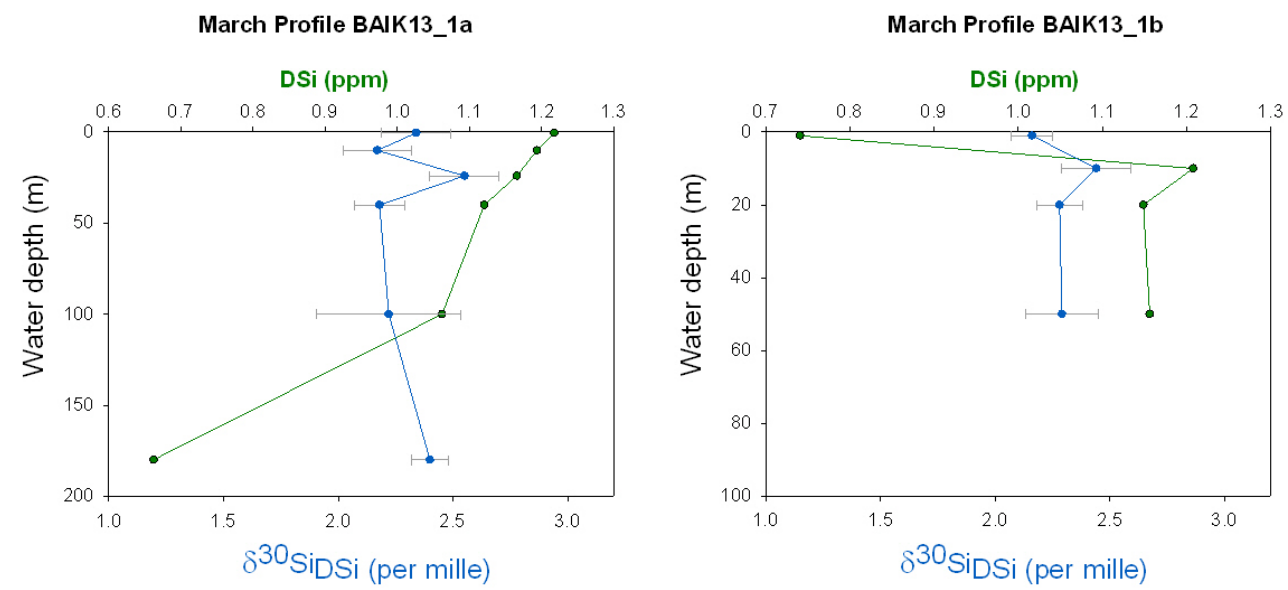

Figure 3. Depicting water column sampling from Lake Baikal (180 m below surface) of DSi concentrations (ppm) shown in green and $\delta^{30} \mathrm{Si}_{\mathrm{DSi}}(\%$ ) signatures in blue. The two sampling intervals (BAIK13-1a and 1b) from March 2013 are both displayed. Note the different

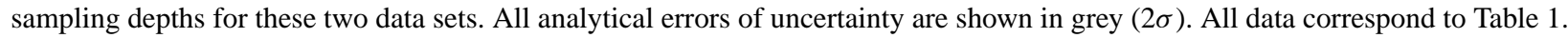

ception of the surface sample at BAIK13-1b (0.74 ppm). As we are unable to fully account for this variability in DSi concentrations, we use a weighted mean of surface water (e.g. above the MTM) $\delta^{30} \mathrm{Si}_{\mathrm{DSi}}$ compositions, collected in March before the diatom bloom period, to act as the baseline isotopic composition (as will be discussed in Sect. 5.1). This is in order to compare with open trap data and estimate the fractionation effect of diatoms $\left(\epsilon_{\text {dissolution }}\right)$. In this case, $\delta^{30} \mathrm{Si}_{\mathrm{DSi}}$ means are $+2.28 \%$ o $( \pm 0.09,95 \%$ confidence; Table 1$)$, although some variability is highlighted between data (e.g. mean square weighted deviation $(\mathrm{MSWD})=4.1, n=10$; Table 1).

ICP-MS data of diatom opal show that ratios of $\mathrm{Al}: \mathrm{Si}$ are all $<0.01$ (data not shown), indicating that contamination in all sediment trap and core samples is negligible. This was confirmed by visual inspection of the diatom samples by light microscopy, prior to analysis (Fig. 2). Sediment trap diatoms are dominated ( $>85 \%)$ by the species Synedra acus var radians. Diatom concentrations show some variability, varying between ca. $3 \times 10^{4}$ and $7 \times 10^{4}$ valves $^{-1}$ wet weight (Fig. 4), although lowest concentrations are seen in the open sediment trap at $1350 \mathrm{~m}$ depth $\left(3 \times 10^{4}\right.$ valves $^{-1}$ wet weight Fig. 4). This is coincident with lowest diatom
(S. acus var radians) valve abundances also ( $86 \%$; Table 2 ). $\delta^{30} \mathrm{Si}_{\text {diatom }}$ data from the open sediment traps show little variability (within analytical uncertainty) down the water column profile in Lake Baikal (Table 2; Fig. 4) with values ranging from +1.11 to $+1.38 \%$ o (weighted mean $+1.23 \%$ o \pm 0.06 at $95 \%$ confidence, MSWD $=2.9, n=10)$. Sequencing (A) traps from May, July and August following the onset of major diatom productivity in early spring show a degree of variability with July and August $\delta^{30} \mathrm{Si}_{\text {diatom }}$ data similar to the open sediment traps but data from May lower at $0.67 \%$ o \pm 0.06 (Table 2). Surface sediment results from BAIK13-1C (0.6$0.8 \mathrm{~cm}$ core depth) and BAIK13-4F $(0.2-0.4 \mathrm{~cm}$ core depth) are very similar to both open $(\mathrm{Z})$ and July-August sequenc-

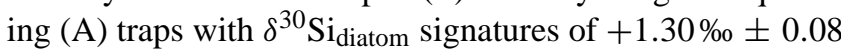
$(2 \sigma)$ and $+1.43 \% \circ \pm 0.13(2 \sigma)$ respectively (Table 2$)$. Open trap total dry mass fluxes show a near-constant value down the Lake Baikal water column (Table 2), with values ranging between $289.64 \mathrm{mg} \mathrm{m}^{-2} \mathrm{~d}^{-1}$ at $1300 \mathrm{~m}$ water depth and $327.32 \mathrm{mg} \mathrm{m}^{-2} \mathrm{~d}^{-1}$ at $900 \mathrm{~m}$ water depth. Sequencing traps show the highest peak in total dry mass fluxes for the month of June $1649.52 \mathrm{mg} \mathrm{m}^{-2} \mathrm{~d}^{-1}$ (although black particulate matter, of unknown origin, is also present) and remain higher (compared to winter months) from July to October (Fig. 5). 


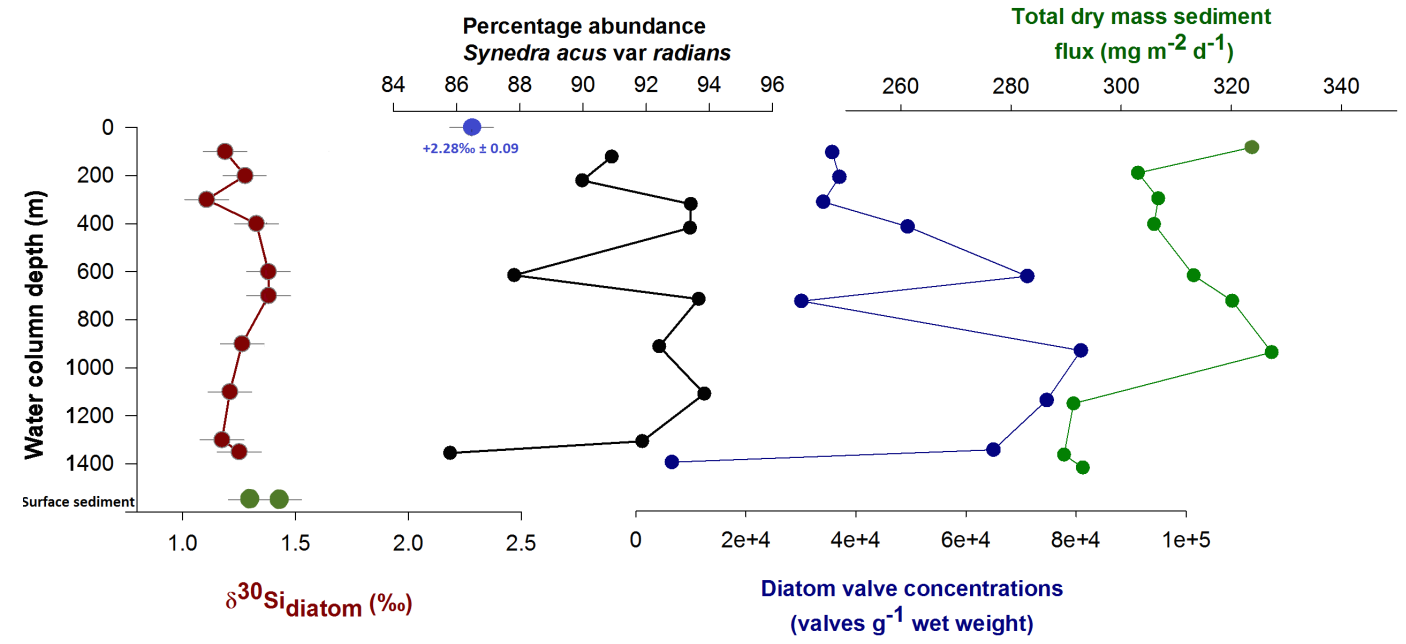

Figure 4. Open sediment trap (2012-2013) data from site BAIK13-1, south basin Lake Baikal (brown symbols). Samples are displayed along a $y$ axis of water column depth. $\delta^{30} \mathrm{Si}_{\text {diatom }}$ data $(\%)$ are expressed with respective analytical errors $(2 \sigma)$ and surface sediment samples from cores BAIK13-1C and BAIK13-4F are also displayed (green symbols) along with the mean March surface (2013) water composition (blue symbol). Percentage abundance of the dominant diatom Synedra acus var radians, diatom concentrations (valves $\mathrm{g}^{-1}$ wet weight) and total dry mass sediment fluxes $\left(\mathrm{mg} \mathrm{m}^{-2} \mathrm{~d}^{-1}\right)$ are also provided. All data apart from diatom concentrations are presented in Table 2.

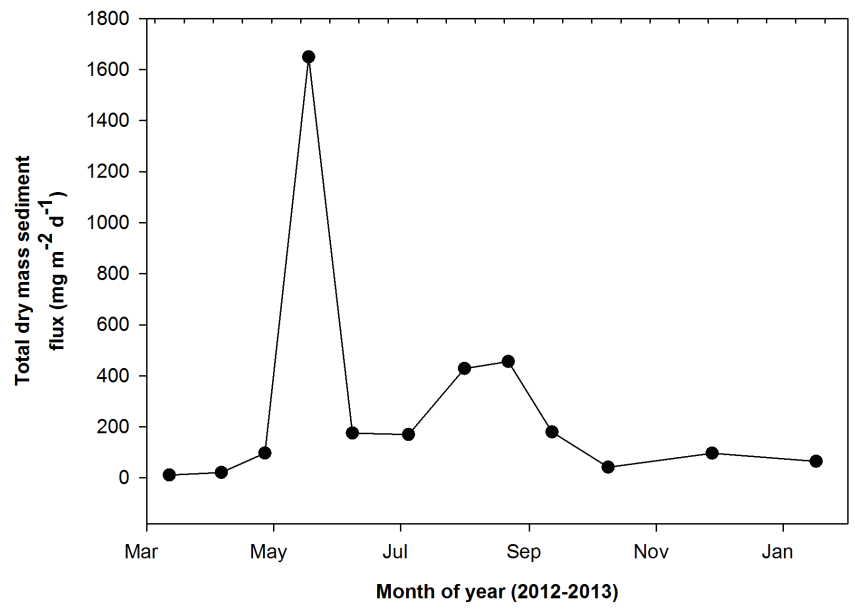

Figure 5. Total dry mass sediment fluxes $\left(\mathrm{mg} \mathrm{m}^{-2} \mathrm{~d}^{-1}\right)$ for monthly sequencing traps, positioned at $100 \mathrm{~m}$ water depth in the South Basin of Lake Baikal (2012-2013).

\section{Discussion}

The extreme continentality of the region around Lake Baikal generates cold, dry winters that create an extensive ice cover over the lake from October/November to May/June (north basin) and from January to April/May (south basin) (Atlas Baikalia, 1993). This ice cover plays a key role in regulating seasonal diatom productivity (as discussed in Sect. 2) with blooms developing following the (1) reductions in ice cover in spring and (2) after mixed-layer stratification in summer (Shimaraev et al., 1994; Popovskaya, 2000; Granin et al., 2000; Jewson et al., 2009; Troitskaya et al., 2014). These blooms are also coincident with periods of overturn in the upper waters of the lake (e.g. above the MTM; Sect. 2). The March $\delta^{30} \mathrm{Si}_{\mathrm{DSi}}$ data in this study were collected when there was no/negligible chlorophyll $a$ in the water column down to a depth of $200 \mathrm{~m}$. Accordingly, we interpret March ${ }^{30} \mathrm{Si}_{\mathrm{DSi}}(+2.28 \% \circ \pm 0.09 ; 95 \%$ confidence interval, $n=10$; Table 1) as reflecting the pre-spring bloom isotopic composition of silicic acid in the mixed layer prior to its uptake and fractionation in subsequent weeks as the spring bloom develops. Whilst the open traps deployed from March 2012 to March 2013 may contain diatoms from both spring and autumnal blooms, we suggest that $\delta^{30} \mathrm{Si}_{\text {diatom }}$ signatures from these traps are primarily derived from the first bloom in spring/summer due to the dominance of (1) spring diatom blooms in the annual record (Popovskaya, 2000), and (2) the dominance of spring/summer (May to August) blooming $S$. acus var radians (Ryves et al., 2003) in the traps (> 85\% relative abundance (Fig. 4). This is supported by total dry mass fluxes from the $100 \mathrm{~m}$ sequencing traps which peak in June to September (Fig. 5). We therefore argue that the open trap data should be primarily reflective of spring to summer silicic acid utilisation in the photic zone and so can be used to trace the fate of surface water signatures through the water column and into the sediment record.

\subsection{Estimations of diatom fractionation factors $(\epsilon)$}

During biomineralisation, diatoms discriminate against the heavier ${ }^{30} \mathrm{Si}$ isotope, preferentially incorporating ${ }^{28} \mathrm{Si}$ into their frustules and leaving ambient waters enriched in ${ }^{30} \mathrm{Si}$. Existing work from culture experiments and marine environments has suggested an $\epsilon$ (the per mil enrichment factor 
between dissolved (DSi) and solid (diatom) phases) during biomineralisation $\left(\epsilon_{\text {uptake }}\right)$ of $-1.1 \pm 0.4$ to $-1.2 \pm 0.2 \%$ o (De La Rocha et al., 1997; Milligan et al., 2004; Varela et al., 2004; Fripiat et al., 2011). Such estimations of $\epsilon_{\text {uptake }}$ have been applied within both closed system (De La Rocha et al., 1997) and open system (Varela et al., 2004) modelling as a means of estimating variations in $\delta^{30} \mathrm{Si}$ compositions, although, as discussed in Sect. 1, more recent evidence from cultured marine diatoms does point to a species-dependent fractionation effect, which could range anywhere between $-0.53 \% \circ \pm 0.11$ (Fragilariaopsis kerguelensis species) and $-2.09 \% \pm 0.09$ (Chaetocerous brevis species) (Sutton et al., 2013).

Monthly data for both $\delta^{30} \mathrm{Si}_{\mathrm{DSi}}$ and $\delta^{30} \mathrm{Si}_{\text {diatom }}$ are not available in order to fully constrain $\epsilon_{\text {uptake }}$ over the course of the diatom growing season in Lake Baikal (e.g. estimating variations between the open and closed system models, where the import/export of DSi and BSi can be more fully estimated from surface waters). Nevertheless, we can apply the data in this context to provide a snapshot of $\epsilon_{\text {uptake, }}$, when a comparison is made between $\delta^{30} \mathrm{Si}_{\mathrm{DSi}}$ initial and the first monthly sequencing trap $\delta^{30} \mathrm{Si}_{\text {diatom }}$ compositions. We select the May $\delta^{30} \mathrm{Si}_{\text {diatom }}$ signatures as we propose it reflects the initiation of the diatom bloom and therefore captures the opal exported (based on total dry mass sediment flux data; Fig. 5) from surface waters at this time. These compositions will therefore most likely derive from DSi initial compositions (March surface waters) before any (or minimal) progressive DSi enrichment occurs. We propose these data for discursive reasons in order to extend the estimations of $\epsilon_{\text {uptake }}$ from lacustrine systems and argue that they act as a snapshot estimation in this instance.

When examining sequencing trap total dry mass sediment fluxes for the year 2012-2013, numbers are greatest for the month of June (Fig. 5). This directly follows the period when $\delta^{30} \mathrm{Si}_{\text {diatom }}$ isotopic compositions are the lowest of the three sequencing traps presented (May 2012= $+0.67 \%$ o $\pm 0.06,2 \sigma)$. Although diatom concentrations are not available for the sequencing traps, we propose that these higher total dry mass sediment fluxes (Fig. 5) capture the exported May 2012 diatom bloom (e.g. the spring bloom) following ice-off and, based on flux data, most likely represent the event more closely associated with pre-bloom surface water (e.g. March) $\delta^{30} \mathrm{Si}_{\mathrm{DSi}}$ compositions $(+2.28 \%$ \pm 0.09 ; $95 \%$ confidence interval, $n=10$; Table 1 ). Although later monthly $\delta^{30} \mathrm{Si}_{\mathrm{DSi}}$ data are not available, it is probable that the heavier isotopic ${ }^{30} \mathrm{Si}_{\text {diatom }}$ compositions of July and $\mathrm{Au}$ gust sequencing traps (Table 2) reflect the progressive enrichment of the DSi surface pool as the bloom develops. On the contrary, open trap data (Table 2) constitute the mean annual ${ }^{30} \mathrm{Si}_{\text {diatom }}$ composition of diatoms, incorporating signatures derived from throughout the year (a mean $\delta^{30} \mathrm{Si}_{\text {diatom }}$ composition of $+1.23 \% \circ \pm 0.06 ; 95 \%$ confidence interval, $n=10$; Table 2).
Although diatom uptake fractionation factors cannot be fully constrained in this study (particularly when addressing open trap $\delta^{30} \mathrm{Si}_{\text {diatom }}$ signatures), due to the absence of comprehensive monthly DSi and BSi data, we can still provide an estimation of $\epsilon_{\text {uptake }}$ for Lake Baikal. However, we emphasise that this is for discussion purposes alone and that in order for this to be a more robust estimation, there is a need for more seasonal investigations. Nevertheless, if we argue that May $\delta^{30} \mathrm{Si}_{\text {diatom }}$ act as the dominant spring bloom composition $(+0.67 \% \circ \pm 0.06,2 \sigma$; Table 2$)$ exported from the surface zone and we compare this with our March 2013 mean pre-bloom spring top water (incorporating 0 to $180 \mathrm{~m}) \delta^{30} \mathrm{Si}_{\mathrm{DSi}}$ composition (e.g. a DSi initial) of $+2.28 \%$ o $( \pm 0.09,95 \%$ confidence interval, $n=10)$ (Table 1$)$, we can derive an estimation of $\epsilon_{\text {uptake }}$ of $-1.61 \%$ (ranging between -1.46 and $-1.70 \%$ when taking account of respective analytical uncertainty). We propose that this reflects more fully the initial uptake of DSi by diatoms, following ice-off and turnover, while later sequential trap data (of July and August; $+1.22 \% \circ \pm 0.08$ and $+1.37 \%$ \pm 0.07 respectively; Table 2 ) quite possibly reflect the progressive enrichment of the surface DSi pool which cannot be constrained here. Although this $\epsilon_{\text {uptake }}$ estimation of $-1.61 \%$ falls within (or just outside of, e.g. $-1.2 \% \circ \pm 0.2$ from Fripiat et al., 2011) analytical uncertainty of existing estimations of $\epsilon_{\text {uptake }}$ (e.g. from temperate/sub-polar marine diatoms, $-1.1 \% \circ \pm 0.4$; De La Rocha et al., 1997), we propose that they highlight the need for further estimations within the literature. This is particularly important within the context of freshwater Si palaeoreconstructions where there is a paucity of laboratory culture experiments, as the handful of in situ measurements derived from lacustrine studies have calculated $\epsilon_{\text {uptake }}$ values closer to $-1.1 \%$ o (e.g. Alleman et al., 2005; Opfergelt et al., 2011). What is more, these estimations of $\epsilon_{\text {uptake }}$ are further compounded by the more recent evidence which has thrown into question the role that species-dependent fractionation factors may take during diatom biomineralisation (e.g. Sutton et al, 2013), although investigations of this in lacustrine environments are still to be conducted.

\subsection{The fate of diatom utilisation and $\delta^{30} \mathrm{Si}_{\text {diatom in }}$ Lake Baikal}

Asides from the discussions surrounding the biological uptake of DSi by diatoms and the seasonal relationship between DSi compositions, the isotopic composition of trap data (Table 2) from down the water column (except for the May sequencing trap) (Table 2) highlights the fact that the isotopic signature incorporated into diatoms in the photic zone during biomineralisation is safely transferred through the water column without alteration, either from dissolution $\left(\epsilon_{\text {dissolution }}\right)$ or other processes. Indeed, $\delta^{30} \mathrm{Si}_{\text {diatom }}$ signatures through the open traps show minimal variation (mean of $+1.23 \%$ o \pm 0.06 at $95 \%$ confidence and MSWD of 2.9, $n=10$; Table 2). 
The role of dissolution is particularly important for the species Synedra acus var radians (which dominates open trap compositions for the year 2012-2013; Table 2) as the literature has demonstrated the fragility of this valve, particularly its sensitivity to water column and surface sediment interface dissolution (Battarbee et al., 2005; Ryves et al., 2003). While this species is sensitive to dissolution, Mackay et al. (1998) have nevertheless documented an increased percentage presence in south basin Lake Baikal sediments over the past ca. 60 years (to between 10 and $20 \%$ relative abundance), thought to represent a biological response to late 20th century warming in this region. Although the majority of dissolution in Lake Baikal occurs at the surface-sediment interface, with only $1 \%$ of phytoplanktonic diatoms becoming incorporated into the sediment record (Ryves et al., 2003; Battarbee et al., 2005), $\delta^{30} \mathrm{Si}_{\text {diatom }}$ in sediment core surface samples (i.e. post burial) at BAIK13-1C $(0.6-0.8 \mathrm{~cm}$ core depth) and at BAIK13-4F $(0.2-0.4 \mathrm{~cm}$ core depth) of $+1.30 \%$ $\pm 0.08(2 \sigma)$ and $+1.43 \%$ o $\pm 0.13(2 \sigma)$ respectively (Fig. 4), are also similar (within uncertainty) to the sediment trap data of $+1.23 \% \circ \pm 0.06$ (95\% confidence). These data confirm that in contrast to previous work (Demarest et al., 2009) there is no $\epsilon_{\text {dissolution }}$ or at least no other alteration of the ${ }^{30} \mathrm{Si}_{\text {diatom }}$ signature from diatoms sinking through the water column and during burial in the sediment record. This in agreement with previous studies on marine diatoms (Wetzel et al., 2014) and validates that $\delta^{30} \mathrm{Si}_{\text {diatom }}$ can be used in lacustrine sediment cores to constrain biogeochemical cycling (building on work by Egan et al., 2012).

\section{Conclusions}

The first $\delta^{30} \mathrm{Si}_{\text {diatom }}$ data from lacustrine sediment traps are presented from Lake Baikal, Siberia, and their use in interpreting the fate of $\delta^{30} \mathrm{Si}_{\text {diatom }}$ in the sediment record is shown. Mean values for open traps $(+1.23 \%$ o \pm 0.06 at $95 \%$ confidence and MSWD of 2.9, $n=10$ ) suggest no alteration to the signal through the water column. Sequencing traps (May, July and August) do show variation in their $\delta^{30} \mathrm{Si}_{\text {diatom }}$ signatures, with May the lowest at $+0.67 \%$ o $( \pm 0.06)$. With total dry mass sediment fluxes highest in June 2012, we argue that May represents the initial diatom bloom export from surface waters. As such, we provide a snapshot estimation of $\epsilon_{\text {uptake }}$ in Lake Baikal of $-1.61 \%$, when comparing May $\delta^{30} \mathrm{Si}_{\text {diatom }}$ compositions and mean surface water March $\delta^{30} \mathrm{Si}_{\mathrm{DSi}}$ compositions $(+2.28 \%$ \pm 0.09 at $95 \%$ confidence). Although monthly synchronous $\delta^{30} \mathrm{Si}_{\mathrm{DSi}}$ and $\delta^{30} \mathrm{Si}_{\text {diatom }}$ are not available to fully constrain $\epsilon_{\text {uptake }}$ (nor indeed any seasonal progressive enrichment of DSi in surface waters) in Lake Baikal surface waters, the data provide a snapshot into stable isotope processes in freshwater systems which to date have not been fully explored. The near-constant $\delta^{30} \mathrm{Si}_{\text {diatom }}$ compositions in open traps demonstrates the full preservation of the signal through the water column and thereby justifies the use and application of the technique in biogeochemical and palaeoenvironmental research. In particular, data highlight the absence of a fractionation factor associated with diatom dissolution ( $\left.\epsilon_{\text {dissolution }}\right)$ down the water column, of particular importance as the diatom species Synedra acus var. radians is known to be sensitive to dissolution with estimations of only up to $5 \%$ making it to the sediment interface (Ryves et al., 2003). This is further reinforced by lake surface sediment data from south basin cores, which also demonstrate the absence of $\epsilon_{\text {dissolution }}$ due to the similar compositions (within uncertainty) of surface sediment $\delta^{30} \mathrm{Si}_{\text {diatom }}$ when compared to open trap data.

Acknowledgements. This project was funded by National Environmental Research Council (NERC) standard grants NE/J00829X/1, $\mathrm{NE} / \mathrm{J} 010227 / 1$ and NE/J007765/1 with research undertaken within the Centre of Environmental Geochemistry, a joint venture between the British Geological Survey and the University of Nottingham. The authors would like to thank Simon Chenery and Thomas Barlow (BGS) for ICP-MS analyses of dissolved silicon concentrations, in addition to Stephen Noble (NIGL) for his assistance and knowledge. Additional thanks go to Suzanne McGowan and Sarah Roberts (University of Nottingham) for their invaluable assistance in the field as well as the numerous other international colleagues that participated in the Lake Baikal March 2013 field season. The authors are indebted to the assistance of Nikolay M. Budnev (Irkutsk State University), the captain and crew of the Geolog research boat and Dmitry Gladkochub (IEC) in facilitating and organising all Russian fieldwork. All ${ }^{210} \mathrm{~Pb}$ dating was conducted at the Environmental Change Research Centre, University College London.

Edited by: A. Shemesh

\section{References}

Alleman, L. Y., Cardinal, D., Cocquyt, C., Plisnier, P. D., Descy, J. P., Kimirei, I., Sinyinza, D., and Andre, L.: Silicon isotopic fractionation in Lake Tanganyika and its main tributaries, J. Great Lakes Res., 31, 509-519, 2005.

Appleby, P. G. and Oldfield, F.: The calculation of ${ }^{210} \mathrm{~Pb}$ dates assuming a constant rate of supply of unsupported ${ }^{210} \mathrm{~Pb}$ to the sediment, Catena, 5, 1-8, 1978.

Atlas Baikalia: "Siberia" Program Interdepartmental Scientific Committee of the SB RAS, Federal'naya Sluzhba Geodezii i Kartografii Rossii, Moscow, 1993 (in Russian).

Battarbee, R. W., Anderson, N. J., Jeppesen, E., and Leavitt, P. R.: Combining palaeolimnological and limnological approaches in assessing lake ecosystem response to nutrient reduction, Freshwater Biol., 50, 1772-1780, 2005.

Cardinal, D., Alleman, L. Y., de Jong, J., Ziegler, K., and Andre, L.: Isotopic composition of silicon measured by multicollector plasma source mass spectrometry in dry plasma mode, J. Anal. Atom. Spectrom., 18, 213-218, 2003.

Cockerton, H. E., Street-Perrott, F. A., Leng, M. J., Barker, P. A., Horstwood, M. S. A., and Pashley, V.: Stable-isotope (H, O, and 
Si) evidence for seasonal variations in hydrology and Si cycling from modern waters in the Nile Basin: implications for interpreting the Quaternary record, Quaternary Sci. Rev., 66, 4-21, 2013.

De La Rocha, C. L.: Opal-based isotopic proxies of paleoenvironmental conditions, Global Biogeochem. Cy., 20, GB4S09, doi:10.1029/2005GB002664, 2006.

De La Rocha, C. L., Brzezinski, M. A., and DeNiro, M. J.: Fractionation of silicon isotopes by marine diatoms during biogenic silica formation, Geochim. Cosmochim. Ac., 61, 5051-5056, 1997.

Demarest, M. S., Brzezinski, M. A., and Beucher, C. P.: Fractionation of silicon isotopes during biogenic silica dissolution, Geochim. Cosmochim. Ac., 73, 5572-5583, 2009.

Egan, K. E., Rickaby, R. E. M., Leng, M. J., Hendry, K. R., Hermoso, M., Sloane, H. J., Bostock, H., and Halliday, A. N.: Diatom silicon isotopes as a proxy for silicic acid utilisation: A Southern Ocean core top calibration, Geochim. Cosmochim. Ac., 96, 174-192, 2012.

Falkner, K. K., Church, M., Measures, C., LeBaron, G., Touron, D., Jeandel, C., Stordal, M. C., Gill, G. A., Mortlock, R. A., and Froelich, P.: Minor and major element chemistry of Lake Baikal, its tributaries, and surrounding hot springs, Limnol. Oceanogr., 42, 329-345, 1997.

Frings, P. J., Clymans, W., Jeppesen, E., Lauridsen, T. L., Struyf, E., and Conley, D. J.: Lack of steady-state in the global biogeochemical Si cycle: emerging evidence from lake Si sequestration, Biogeochemistry, 117, 255-277, doi:10.1007/s10533-013-9944z, 2014.

Fripiat, F., Cavagna, A.-J., Dehairs, F., Speich, S., André, L., and Cardinal, D.: Silicon pool dynamics and biogenic silica export in the Southern Ocean inferred from Si-isotopes, Ocean Sci., 7, 533-547, doi:10.5194/os-7-533-2011, 2011.

Fripiat, F., Cavagna, A.-J., Dehairs, F., de Brauwere, A., André, L., and Cardinal, D.: Processes controlling the Si-isotopic composition in the Southern Ocean and application for paleoceanography, Biogeosciences, 9, 2443-2457, doi:10.5194/bg-9-24432012, 2012.

Georg, R. B., Reynolds, B. C., Frank, M., and Halliday, A. N.: New sample preparation techniques for the determination of $\mathrm{Si}$ isotopic compositions using MC-ICPMS, Chem. Geol., 235, 95$104,2006$.

Granin, N. G., Jewson, D. H., Gnatovsky, R. Y., Levin, L. A., Zhdanov, A. A., Gorbunova, L. A., Tsekhanovsky, V. V., Doroschenko, L. M., and Mogilev, N. Y.: Turbulent mixing under ice an the growth of diatoms in Lake Baikal, Verhein Int. Ver. Lomnology, 27, 1-3, 2000.

Gronskaya, T. P. and Litova, T. E.: Kratkaya Harakteristika Vodnogo Balansa Ozera Baikal za Period 1962-1988 (Short characteristics of the water balance of Lake Baikal during 19621988), Gidrometeoizdsat, Leningrad, 1991.

Hendry, K. R. and Brzezinski, M. A.: Using silicon isotopes to understand the role of the Southern Ocean in modern and ancient biogeochemistry and climate, Quaternary Sci. Rev., 89, 13-26, 2014.

Hohmann, R., Kipfer, R., Peeters, F., Piepke, G., Imboden, D. M., and Shimaraev, M. N.: Deep-water renewal in Lake Baikal, Limnol. Oceanogr., 42, 841-855, 1997.

Hughes, H. J., Delvigne, C., Korntheuer, M., de Jong, J., Andre, L., and Cardinal, D.: Controlling the mass bias introduced by an- ionic and organic matrices in silicon isotopic measurements by MC-ICP-MS, J. Anal. Atom. Spectrom., 26, 1892-1896, 2011.

Jewson, D. H., Granin, N. G., Zhdanov, A. A., and Gnatovsky, R. Y.: Effect of snow depth on under-ice irradiance and growth of Aulacoseira baicalensis in Lake Baikal, Aquat. Ecol., 43, 673-679, 2009.

Johnson, C. M., Beard, B. L., and Albarède, F.: Overview and general concepts, in: Geochemistry of Nontraditional Stable Isotopes, Reviews in Mineralogy and Geochemistry, edited by: Johnson, C. M., Beard, B. L., and Albarède, F., 1-24, 2004.

Kipfer, R. and Peeters, F.: Some speculations on the possibility of changes in deep-water renewal in Lake Baikal and their consequences, in: Lake Baikal: A Mirror in Time and Space for Understanding Global Change Processes, edited by: Minoura, K., Elsevier, Chapter 24, ISBN: 978-0-444-50434-0, 273-280, 2000.

Kipfer, R., AeschbachHertig, W., Hofer, M., Hohmann, R., Imboden, D. M., Baur, H., Golubev, V., and Klerkx, J.: Bottomwater formation due to hydrothermal activity in Frolikha Bay, Lake Baikal, eastern Siberia, Geochim. Cosmochim. Ac., 60, 961971, 1996.

Leng, M. J., Swann, G. E. A., Hodson, M. J., Tyler, J. J., Patwardhan, S. V., and Sloane, H. J.: The potential use of silicon isotope composition of biogenic silica as a proxy for environmental change, Silicon, 1, 65-77, 2009.

Mackay, A., Flower, R., Kuzmina, A., Granina, L., Rose, N., Appleby, P., Boyle, J., and Battarbee, R.: Diatom succession trends in recent sediments from Lake Baikal and their relation to atmospheric pollution and to climate change, Philos. T. Roy. Soc. B, 353, 1011-1055, 1998.

Milligan, A. J., Varela, D. E., Brzezinski, M. A., and Morel, F. O. M. M.: Dynamics of silicon metabolism and silicon isotopic discrimination in a marine diatom as a function of p $\mathrm{CO}_{2}$, Limnol. Oceanogr., 49, 322-329, 2004.

Müller, B., Maerki, M., Schmid, M., Vologina, E. G., Wehrli, B., Wuest, A., and Sturm, M.: Internal carbon and nutrient cycling in Lake Baikal: sedimentation, upwelling, and early diagenesis, Global Planet. Change, 46, 101-124, 2005.

Opfergelt, S., Eiriksdottir, E. S., Burton, K. W., Einarsson, A., Siebert, C., Gislason, S. R., and Halliday, A. N.: Quantifying the impact of freshwater diatom productivity on silicon isotopes and silicon fluxes: Lake Myvatn, Iceland, Earth. Planet. Sc. Lett., 305, 73-82, 2011.

Panizzo, V., Crespin, J., Crosta, X., Shemesh, A., Masse, G., Yam, R., Mattielli, N., and Cardinal, D.: Sea ice diatom contributions to Holocene nutrient utilization in East Antarctica, Paleoceanography, 29, 328-342, 2013.

Pichevin, L. E., Reynolds, B. C., Ganeshram, R. S., Cacho, I., Pena, L., Keefe, K., and Ellam, R. M.: Enhanced carbon pump inferred from relaxation of nutrient limitation in the glacial ocean, Nature, 459, 1114-1198, 2009.

Pichevin, L., Ganeshram, R. S., Reynolds, B. C., Prahl, F., Pedersen, T. F., Thunell, R., and McClymont, E. L.: Silicic acid biogeochemistry in the Gulf of California: Insights from sedimentary Si isotopes, Paleoceanography, 27, PA2201, doi:10.1029/2011PA002237, 2012.

Popovskaya, G. I.: Ecological monitroing of phytoplankton in Lake Baikal, Aquat. Ecosyst. Health, 3, 215-225, 2000. 
Ravens, T. M., Kocsis, O., Wuest, A., and Granin, N.: Smallscale turbulence and vertical mixing in Lake Baikal, Limnol. Oceanogr., 45, 159-173, 2000.

Reynolds, B. C., Aggarwal, J., André, L., Baxter, D., Beucher, C., Brzezinski, M. A., Engström, E., Georg, R.B., Land, M., Leng, M. J., Opfergelt, S., Rodushkin, I., Sloane, H. S., van den Boorn, S. H. J. M., Vroon, P. Z., and Cardinal, D.: An interlaboratory comparison of $\mathrm{Si}$ isotope reference materials. J. Anal. Atom. Spectrom., 22, 561-568, 2007.

Ryves, D. B., Jewson, D. H., Sturm, M., Battarbee, R. W., Flower, R. J., Mackay, A. W., and Granin, N. G.: Quantitative and qualitative relationships between planktonic diatom communities and diatom assemblages in sedimenting material and surface sediments in Lake Baikal, Siberia, Limnol. Oceanogr., 48, 1643-1661, 2003.

Sherstyankin, P. P., Alekseev, S. P., Abramov, A. M., Stavrov, K. G., De Batist, M., Hus, R., Canals, M., and Casamor, J. L.: Computer-based bathymetric map of Lake Baikal, Dokl. Akad. Nauk, 408, 102-107, 2006.

Shimaraev, M. N. and Granin, N. G.: Temperature stratification and the mechanisms of convection in Lake Baikal, Dokl. Akad. Nauk, $321,1991$.

Shimaraev, M., Verbolov, V., Granin, N., and Sherstyankin, P.: Physical limnology of Lake Baikal: A Review, Baikal International Centre for Ecological Research, Irkutsk \& Okayama, 81 pp., 1994.

Street-Perrott, F. A., Barker, P. A., Leng, M. J., Sloane, H. J., Wooller, M. J., Ficken, K. J., and Swain, D. L.: Towards an understanding of late Quaternary variations in the continental biogeochemical cycle of silicon: multi-isotope and sediment-flux data for Lake Rutundu, Mt Kenya, East Africa, since $38 \mathrm{ka}$ BP, J. Quaternary Sci., 23, 375-387, 2008.
Sutton, J. N., Varela, D. E., Brzezinski, M. A., and Beucher, C. P. Species-dependent silicon isotope fractionation by marine diatoms, Geochim. Cosmochim. Ac., 104, 300-309, 2013.

Swann, G. E. A., Leng, M. J., Juschus, O., Melles, M., BrighamGrette, J., and Sloane, H. J.: A combined oxygen and silicon diatom isotope record of Late Quaternary change in Lake El'gygytgyn, North East Siberia, Quaternary Sci. Rev., 29, 774 786, 2010.

Tréguer, P. J. and De La Rocha, C. L.: The world ocean silica cycle, Ann. Rev. Mar. Sci., 5, 477-501, 2013.

Troitskaya, E., Blinov, V., Ivanov, V., Zhdanov, A., Gnatovsky, R., Sutyrina, E., and Shimaraev, M.: Cyclonic circulation and upwelling in Lake Baikal, Aquat. Sci., 77, 171-182, doi:10.1007/s00027-014-0361-8, 2014.

Varela, D. E., Pride, C. J., and Brzezinski, M. A.: Biological fractionation of silicon isotopes in Southern Ocean surface waters, Global Biogeochem. Cy., 18, doi:10.1029/2003GB002140, 2004.

Weiss, R. F., Carmack, E. C., and Koropalov, V. M.: Deep-water renewal and biological production in Lake Baikal, Nature, 349, 665-669, 1991.

Wetzel, F., de Souza, G. F., and Reynolds, B. C.: What controls silicon isotope fractionation during dissolution of diatom opal?, Geochim. Cosmochim. Ac., 131, 128-137, 2014. 